\title{
A COMPARISON OF SELF-REPORT MEASURES OF CALLOUS-UNEMOTIONAL TRAITS AMONG INCARCERATED YOUTH
}

\section{Associations With Aggression, Conduct Disorder, and Offending Behavior}

\author{
JAMES V. RAY \\ University of Texas at San Antonio \\ PEDRO PECHORRO \\ RUI ABRUNHOSA GONÇALVES \\ University of Minho
}

\begin{abstract}
The current study compared the psychometric properties and incremental validity of the callous-unemotional (CU) traits dimensions from four self-report measures of youth psychopathic traits, including the Antisocial Process Screening Device Self-Report version (APSD-SR), the Youth Psychopathic Traits Inventory (YPI), Youth Psychopathic Traits Inventory-Short version (YPI-S), and the Inventory of Callous-Unemotional Traits (ICU) among a sample of male youth incarcerated in Portuguese detention centers $(N=221)$. Across these measures, estimates of reliability and internal consistency were generally good; however, the correlations between measures ranged from very low to high suggesting moderate convergent validity. With regard to incremental validity, the Callousness dimension of the ICU was the best predictor of aggression, conduct disorder, and crime seriousness, whereas the Uncaring dimension of the ICU was the best predictor of age of crime onset. The current findings have important implications regarding the assessment of CU traits.
\end{abstract}

Keywords: aggression; callous-unemotional traits; crime; conduct disorder; juvenile delinquency

D sychopathy is a multidimensional construct that consists of affective (e.g., lack of remorse, guilt, and callousness), interpersonal (e.g., manipulative and conning), as well as behavioral (e.g., impulsivity and externalizing behaviors) components (e.g., Skeem, Polaschek, Patrick, \& Lilienfeld, 2011). One approach to extending psychopathy to youth

\footnotetext{
AUTHORS' NOTE: This study was supported by the Portuguese Foundation for Science and Technology (FCT; Grant SFRH/BPD/86666/2012) with co-financing of the European Social Fund (POPH/FSE), the Portuguese Ministry of Education and Science through national funds, and co-financed by FEDER under the PT2020 Partnership Agreement (UID/PSI/01662/2013). We wish to thank the following Portuguese juvenile detention centers for their collaboration: Bela Vista, Mondego, Navarro de Paiva, Olivais, Padre António Oliveira, Santo António, Santa Clara, Prisão-Escola de Leiria. Correspondence concerning this article should be addressed to James V. Ray, Department of Criminal Justice, University of Texas at San Antonio, 501 W. Cesar E. Chavez Blvd., San Antonio, TX 78207; e-mail: james.ray@utsa.edu.
} 
has focused specifically on the affective components of psychopathy, appropriately termed callous-unemotional (CU) traits (Frick, Ray, Thornton, \& Kahn, 2014). CU traits identify a subgroup of antisocial youth characterized by a lack of remorse, callousness, and diminished emotional responsivity (Frick et al., 2014). The clinical importance of these traits for identifying a distinct subgroup of antisocial youth is evident in the recent adoption of the "With Limited Prosocial Emotions" specifier to conduct disorder (CD) in the Diagnostic and Statistical Manual of Mental Disorders (5th ed.; DSM-5; American Psychiatric Association, 2013; Frick et al., 2014). This also highlights the need for the development of evidence-based measurements of the CU construct to accurately diagnose such individuals and avoid potential pitfalls of poor measurement that would be particularly detrimental to clinical assessment (e.g., false positives and false negatives).

Although not without limitations, the self-report approach to capturing $\mathrm{CU}$ traits has several benefits, and a variety of self-report measures have recently emerged to assess this construct. Research has been somewhat limited, in that only a few studies have simultaneously examined and compared multiple self-report measures of CU traits. The current study attempts to build on a limited body of research by examining some of the psychometric properties, convergent validity, as well as criterion-related validity of four predominant self-report measures designed to capture CU traits among youth: the Antisocial Process Screening Device (APSD; Frick \& Hare, 2001), the Inventory of Callous-Unemotional Traits (ICU; Kimonis et al., 2008), the Youth Psychopathic Traits Inventory (YPI; Andershed, Kerr, Stattin, \& Levander, 2002), and a recently introduced short version of the YPI, the YPI-S (van Baardewijk et al., 2010).

\section{SELF-REPORT MEASURES OF CU TRAITS}

Several measures have been developed for assessing psychopathic traits among youth. One of the most predominant measures is the Psychopathy Checklist-Youth Version (PCL:YV; Forth, Kosson, \& Hare, 2003), which was derived from the Psychopathy Checklist-Revised (PCL-R; Hare, 2003). Both these measures have been found to capture two distinct factors of psychopathy: the interpersonal-affective and antisocial components. Although clinical assessments of psychopathy such as the PCL:YV have shown good validity and reliability (Kosson, Cyterski, Steuerwald, Neumann, \& Walker-Matthews, 2002), they are also somewhat limited, as they require extensive training and administration time as well as collateral file reviews (e.g., institutional records). Attempts to address these limitations have resulted in the development of various self-report psychopathy measures. Despite criticisms of the self-report approach to measuring psychopathy, research consistently shows that such measures provide reliable and accurate assessments of psychopathic traits (Vaughn \& Howard, 2005). An important aspect of these measures is that they were designed to capture psychopathy as a multidimensional construct and are therefore able to distinctly measure the affective component of psychopathy (i.e., CU traits). However, each of these measures is based on a somewhat different conceptual and operational approach to measuring CU traits, and only a few studies have comparatively examined these measures.

One of the most widely used self-report measures of psychopathic traits among youth is the APSD. The APSD is based on the PCL:YV and was designed to capture a similar twofactor structure (i.e., impulsive/conduct problems [I/CP] and callous/unemotional [C/U] traits; Frick \& Hare, 2001). Vitacco, Rogers, and Neumann (2003) subsequently identified 
a three-factor structure that also included a narcissism factor. In either case, a distinct CU dimension emerges, and a considerable amount of research has examined its psychometric properties and predictive utility. For example, research has found that the CU scale of the APSD is predictive of conduct problems (Dadds, Fraser, Frost, \& Hawes, 2005; Muñoz \& Frick, 2007; Poythress, Dembo, Wareham, \& Greenbaum, 2006), aggression (Marsee, Silverthorn, \& Frick, 2005), and delinquency (Frick, Stickle, Dandreaux, Farrell, \& Kimonis, 2005). Recently, Pechorro, Maroco, Poiares, and Vieira (2013) found that the APSD CU scale distinguished between a community and incarcerated sample of Portuguese youth even when accounting for the other subscales. Despite the good concurrent and predictive utility that the APSD CU scale has shown, it has evinced fairly low internal consistency and has been criticized for being based on only a few items and having only three response options (Poythress, Douglas, et al., 2006).

The ICU was developed to address these limitations of the APSD and to provide a more comprehensive measure of CU traits (Kimonis et al., 2008). Six items were derived from each of the four items that most consistently loaded on the APSD CU scale which resulted in a 24-item measure, and an additional response option was included for items in the development of the ICU. Research has quickly accumulated showing that the ICU total score has good predictive and concurrent validity. For instance, the ICU has consistently shown concurrent positive associations with a variety of externalizing outcomes (e.g., delinquency, CD, and aggression) across a diverse range of samples (Essau, Sasagawa, \& Frick, 2006; Kimonis et al., 2008; Roose, Bijttebier, Decoene, Claes, \& Frick, 2010) and has been found to be predictive of adult criminal behavior (Kahn, Byrd, \& Pardini, 2013). In addition, the ICU total score has shown acceptable internal reliability across a wide range of studies (Frick et al., 2014).

Although the ICU was not originally intended to capture a three-factor structure, factor analytic research has consistently found that an overarching CU construct with three lower-order factors (i.e., callousness, uncaring, and unemotional) is the best-fitting model, and that this structure is robust across a range of samples (Essau et al., 2006; Fanti, Frick, \& Georgiou, 2009; Kimonis et al., 2008). Although a three-factor structure of the ICU is well supported, questions remain regarding the utility of the subscales. First, while the fit indices across these studies suggest that the three-factor structure is the best-fitting model, they require post hoc modifications and even then are quite modest. Second, it is not clear if the factor structure represents some method variance due to the wording (i.e., positive vs. negative) of the items that make up each individual scale (Frick \& Ray, 2015; Hawes et al., 2014). Finally, research on the criterion validity of the subscales has found that the Callousness and Uncaring subscales tend to associate more strongly with measures of antisocial outcomes (e.g., bullying, aggression, and delinquency) compared with the Unemotional scale (Essau et al., 2006; Fanti et al., 2009; Kimonis et al., 2008).

The YPI, however, is a 50-item measure that was designed to capture the three-factor model of psychopathy among non-justice-involved youth and has 10 subscales. Among these subscales, three comprise a CU dimension (Andershed et al., 2002). Thus, the YPI captures CU traits as a distinct, multidimensional component of the broader psychopathy construct. Factor analytic studies have consistently found support for this three-factor structure of the YPI (Colins, Bijttebier, Broekaert, \& Andershed, 2014; Hillege, Das, \& de Ruiter, 2010; van Baardewijk et al., 2010). The three subscales comprising the YPI's CU 
dimension (callousness, remorselessness, and unemotionality) seem to conceptually correspond to the three subscales of the ICU (callousness, uncaring, and unemotional, respectively; Ansel, Barry, Gillen, \& Harrington, 2015).

The majority of studies have examined the YPI at the dimension level providing information regarding the internal reliability and validity (convergent and criterion) for the $\mathrm{CU}$ dimension. Studies have generally reported good internal consistency for the CU dimension (Colins et al., 2014; Declercq, Markey, Vandist, \& Verhaeghe, 2009; Seals, Sharp, Ha, \& Michonski, 2012; van Baardewijk et al., 2010) with some exceptions (Hillege et al., 2010). In terms of validity, research is mixed with regard to the YPI's convergence with the affective factor of the PCL:YV. That is, some studies have found positive associations (Andershed, Hodgins, \& Tengstrom, 2007; Dolan \& Rennie, 2006), whereas others have failed to find any association at all (Skeem \& Cauffman, 2003).

In support of the construct validity of the CU dimension of the YPI, research has found it to be positively associated with conduct problems (van Baardewijk et al., 2010), selfreported delinquency (Declercq et al., 2009), substance use (Hillege et al., 2010), and aggression (Seals et al., 2012). Few studies have examined the properties of the subscales of the CU dimension. Those that have tend to report low internal reliability, particularly for the Callousness scale (Colins et al., 2014; Hillege et al., 2010; Skeem \& Cauffman, 2003). Beyond the reliability of the scales, the extant research on the criterion validity of the subscales of the YPI is virtually non-existent as most studies tend to focus on the higher-order dimensions.

A shortened version of the YPI was recently developed (YPI-S) to reduce administration time for use in large multivariate studies (van Baardewijk et al., 2010). The YPI-S mimics the same three-factor structure of the original YPI (Colins, Noom, \& Vanderplasschen, $2012)$ but due to the reduced number of items $(n=18)$ the subscales are not included. While research on the YPI-S CU scale is somewhat limited given its recent development, there are a few studies that provide insight into its utility. For example, the YPI-S CU dimension has shown positive associations with conduct problems and violent delinquency (Colins et al., 2012; Vahl et al., 2014). Both of these studies reported fairly low internal consistency (i.e., $\alpha<.70)$ for the CU factor.

\section{COMPARISON OF SELF-REPORT CU MEASURES}

Comparisons of these self-report measures of CU traits can provide insight into the conceptual and operational approaches that might be most useful for identifying a particularly severe subgroup of antisocial youth. While cross-sample comparisons of these measures are perceptive, research comparing these measures within a shared sample helps reduce population heterogeneity that might influence the functioning of these measures and enhance comparisons. Few of the past studies evaluating the psychometric properties of CU measures simultaneously included multiple self-report measures of CU traits. Among those that did, the majority of them included only two unique measures or did not report on the CU dimension specifically. For example, in their examination of the YPI and APSD, Poythress, Dembo, et al. (2006) found that the respective CU factors both showed poor internal consistency ( $\alpha=.57$ and .45 , respectively). While they did find that the two scales were positively correlated, the correlation coefficient was quite small $(r=.24)$. Interestingly, they found the YPI CU scale to be negatively correlated with externalizing behavior, while the 
APSD CU scale showed a positive correlation. Seals et al. (2012) compared scores on the YPI CU to scores on the APSD CU scale. They too found poor internal consistencies for the APSD CU scale, while the alpha for the YPI CU scale was above the recommended .70. Although they did find that the YPI CU scale correlated positively with measures of rule breaking and aggression, they did not examine those associations for the APSD. Inconsistent with the findings of Poythress, Douglas, et al. (2006), they found stronger evidence for the convergent validity of the two scales $(r=.45)$. Colins et al. (2014) compared the APSD CU, the YPI CU, and the YPI-S CU scales. Consistent with the prior two studies, they found poor internal consistency for the APSD CU scale and acceptable internal consistency for both the YPI and the YPI-S. In terms of convergent validity, the YPI CU scale correlated positively with the APSD CU scale $(r=.34)$, while the YPI-S CU scale was not related to the APSD CU scale. Finally, multivariate analyses examining associations with external criteria while controlling for the other subscales found that all three scales showed unique associations with vandalism, yet the APSD CU scale was the only one to show unique associations with aggression.

Few studies have compared the ICU with other self-report measures of CU traits among a shared sample. Roose, Bijttebier, Van der Oord, Claes, and Lilienfeld (2013) compared the ICU with the YPI. Both measures showed acceptable internal consistency and similar associations with performance on a lab task designed to assess motivational and selfregulatory features. Vaughn et al. (2011) also compared the YPI with the ICU and found acceptable internal consistency for the YPI CU scale and excellent internal consistency for the ICU and its subscales. The ICU total score correlated positively with the YPI CU scale $(r=.33)$ and to a lesser extent so did the subscales of the ICU. Roose et al. (2010) contrasted the APSD to the ICU. Compared with the APSD CU scale, the ICU showed good internal consistency. In addition, they found fairly strong positive correlations between the ICU total and its subscales with the APSD CU scale. While they did not examine the association between the APSD CU scale and antisocial outcomes, they did find that the ICU and its subscales correlated positively with a composite measure of delinquency.

In a recent more comprehensive study, Ansel et al. (2015) compared the utility of four self-port measures of CU traits, including the APSD, YPI, ICU, and the Child Psychopathy Scale (CPS; Lynam, 1997). They examined the convergent validity among these scales and compared each measure in their ability to predict antisocial outcomes (i.e., aggression, delinquency, and conduct problems) among a sample of at-risk adolescent males. Consistent with prior research, the APSD CU scale showed exceptionally poor internal consistency. While the YPI CU scale yielded relatively high internal consistency, it was still not acceptable and the internal consistency reported for each of the subscales was even lower. The ICU total score appeared to be the most reliable. The internal consistencies of the subscales of the ICU were low with the exception of the Uncaring subscale. They also found considerable support with regard to the convergence of the higher-order CU scales for the APSD, ICU, and YPI. With the exception of the Unemotional scales, the analogous subscales across the YPI and ICU were positively correlated. Finally, regression models suggested that the ICU Callous subscale and the ICU Uncaring subscale were the best predictors of aggression and delinquency, respectively. Despite the contribution of the study, the authors point out several limitations, including limited cross-cultural generalizability and reliance on a predominantly White male sample. 


\section{CURRENT STUDY}

In the current study, we attempt to address the gap in the literature that few studies have examined and compared multiple self-report measures of youth CU traits in a single homogeneous sample. In addition, no study has yet compared multiple CU measures among a culturally distinct sample of justice-involved youth. In this study, we compare the utility of the APSD, ICU, YPI, and YPI-S across a variety of psychometric properties among a Portuguese sample of male youth who have been detained in the juvenile justice system. By doing so, we hope to contribute to a growing body of research on the usefulness of selfreport measures of CU traits.

\section{METHOD}

\section{PARTICIPANTS}

Male inmates from the eight nation-wide juvenile detention centers managed by the Portuguese Ministry of Justice voluntarily agreed to participate in the current study $(N=$ 221). They were all detained by the court's decision. Incarceration into juvenile detention centers is the most severe sanction a Portuguese court can impose on juvenile offenders. Seven of the detention centers are considered low to medium security, and one is considered maximum security (exclusively used for youth tried as adults).

The participants $\left(M_{\text {age }}=16.75\right.$ years; $S D=1.41$ years; age range $=13-20$ years $)$ were White Europeans (54.3\%), Black Africans (20.5\%), mixed race South Americans (18.6\%), and members of other ethnic minorities (6.8\%). Most of the participants came from an urban background $(92.8 \%)$. Their first criminal problems occurred early in their lives $(M=11.33$ years, $S D=2.24$ years $)$, most were detained before they were 16 years old $(M=15.46, S D=1.31)$, and had been convicted to an average of 21 months in detention $(M=20.67, S D=6.69)$. The majority of the sample $(87.6 \%)$ was convicted of having committed serious and/or violent crimes (e.g., homicide, robbery, assault, rape).

\section{MEASURES}

The APSD-Self-Report (APSD-SR; Caputo, Frick, \& Brodsky, 1999; Frick \& Hare, 2001 ) is a multidimensional 20-item measure designed to assess psychopathic traits in adolescents and is modeled after the PCL-R (Hare, 2003). Each item is scored on a 3-point ordinal scale ranging from "never" to "often." The total score, as well as each dimension score, is obtained by adding the respective items. Some studies (e.g., Frick, Bodin, \& Barry, 2000; Frick \& Hare, 2001) reported three main factors: CU, Narcissism, and Impulsivity. Higher scores are indicative of more psychopathic traits. CU traits are assessed by a single six-item factor on the APSD, but the internal consistencies for the CU dimension have not been as high as it is usually found for the APSD total score (Bijttebier \& Decoene, 2009; Colins et al., 2014; Muñoz \& Frick, 2007). The Portuguese validation of the APSD-SR (Pechorro, Hidalgo, Nunes, \& Jiménez, 2015; Pechorro et al., 2013) was used. The internal consistency for the current study estimated by Cronbach's alpha was .81 .

The YPI (Andershed et al., 2002) is a 50-item self-report measure designed to assess the core personality traits of the psychopathic personality constellation in youth aged 12 years old and up. Each item is scored on an ordinal 4-point Likert-type scale ranging from "does not apply at all" to "applies very well." The YPI consists of 10 subscales (with five 
items each) designed in line with Cooke and Michie's (2001) three-dimensional conceptualization of the psychopathy construct, namely the Grandiose-Manipulative dimension, the CU dimension, and the Impulsive-Irresponsible dimension. More specifically, the Grandiose-Manipulative dimension consists of the Dishonest Charm, Grandiosity, Lying, and Manipulation subscales; the CU dimension consists of the Callousness, Unemotionality, and Remorselessness subscales; and the Impulsive-Irresponsible dimension consists of the Impulsivity, Thrill-seeking, and Irresponsibility subscales. Higher scores reflect an increased presence of the characteristics associated with psychopathic traits. The Portuguese validation of the YPI (Pechorro, Andershed, Ray, Maroco, \& Gonçalves, 2015) was used. The internal consistency for the current study estimated by Cronbach's alpha was .87.

The YPI-S (Colins et al., 2012; van Baardewijk et al., 2010) is an 18-item self-report shorter version of the original YPI (Andershed et al., 2002) designed to measure psychopathic-like traits in adolescents. All 18 items come from the original YPI. Each item in the YPI-S is scored on a 4-point Likert-type scale ranging from "does not apply at all" to "applies very well." The YPI-S can be scored by simply adding the items. The YPI-S has a similar factor structure to the original YPI (see above). The Portuguese validation of the YPI-S (Pechorro, Andershed, et al., 2015) was used. The internal consistency for the current study estimated by Cronbach's alpha was .82 .

The ICU (Essau et al., 2006; Kimonis et al., 2008) is a 24-item self-report scale designed to assess callous and unemotional traits in youth derived from the CU subscale of the APSD (Frick \& Hare, 2001). Each item is scored on a 4-point scale ranging from "not at all true" to "definitely true." Scores are calculated by reverse-scoring the positively worded items, and then summing the items to obtain a total score. Using confirmatory factor analysis, it was possible to identify three independent factors, namely Callousness, Unemotional, and Uncaring. All items loaded onto a general CU factor. Higher scores indicate an increased presence of CU traits. The Portuguese validation of the ICU (Pechorro, Ray, Barroso, Maroco, \& Gonçalves, 2016) was used. The internal consistency for the current study, estimated by Cronbach's alpha, was ICU total $=.90$.

The Reactive-Proactive Aggression Questionnaire (RPQ; Raine et al., 2006) is a selfreport measure that distinguishes between reactive and proactive aggression. The RPQ consists of 23 items rated on a 3 -point ordinal scale $(0=$ never, $1=$ sometimes, $2=$ often $)$. A total of 11 items assess reactive aggression (e.g., "Reacted angrily when provoked by others") and 12 items assess proactive aggression (e.g., "Hurt others to win a game"). Summed scores provide measures of reactive or proactive aggression, as well as total aggression. Higher scores indicate increased levels of aggression. The RPQ is appropriate for use with youth and young adults. The Portuguese validation of the RPQ (Pechorro, Ray, Raine, Maroco, \& Gonçalves, 2015) was used. Internal consistency for the present study estimated by Cronbach's alpha was .93 .

The Sellin-Wolfgang Index of Crime Seriousness (ICS; Wolfgang et al., as cited in White et al., 1994) guided the ordinal delinquency seriousness classification of the official court reports. Level 0 consists of no delinquency. Level 1 consists of minor delinquency committed at home such as stealing minor amounts of money from mother's purse. Level 2 consists of minor delinquency outside the home, including shoplifting something worth less than 5 euros, vandalism and minor fraud (e.g., not paying bus fare). Level 3 consists of moderately serious delinquency such as any theft over 5 euros, gang fighting, carrying 
weapons, and joyriding. Level 4 consists of serious delinquency such as car theft and breaking and entering. Level 5 consists of having performed at least two of each of the behaviors in Level 4.

A questionnaire was constructed to describe the sociodemographic and criminal characteristics of the participants, to offer a descriptive account of the sample, and to explore the association of some of these variables (e.g., age of crime onset) with CU traits scores. This questionnaire included variables such as participants' age, ethnic group, origin (rural vs. urban), level of schooling completed, socioeconomic status, age of crime onset, age of first incarceration, length of the conviction, and use of physical violence in committing crimes. DSM-5's CD (American Psychiatric Association, 2013) was assessed using the official diagnostic criteria (i.e., the standard method described in the DSM-5). Among the current sample, the percentage of participants who were diagnosed with CD was considerably high (94.1\%). A CD scale was also created based on the 15 items used to diagnosis CD (see, for example, Skilling, Quinsey, \& Craig, 2001). The 15 dichotomous items $($ no $=0$, yes $=1)$ were summated to obtain a total continuous score. Thus, higher scores indicate a higher number of positively endorsed indicators of CD. Based on the Kuder-Richardson coefficient, the internal consistency of the CD scale was acceptable (.77).

\section{PROCEDURES}

Authorization to assess youth was obtained from the General Directorate of Reintegration and Prison Services-Ministry of Justice (Direção-Geral de Reinserção e Serviços PrisionaisMinistério da Justiça). The detainees from the eight existing Portuguese Juvenile Detention Centers that admit male youth were informed about the nature of the study and asked to voluntarily participate. The participation rate was relatively high $(92 \%)$ despite not compensating youth in any way for participation. Not all young people agreed or were able to participate; reasons for this included refusal to participate $(5 \%)$, inability to participate due to not understanding the Portuguese language $(2 \%)$, and inability to participate due to security issues (1\%). The measures were administered by means of individual face-to-face interviews in an appropriate setting. It was stressed that there were no right or wrong answers, and that for each item the youth should consider what he generally thinks or feels. Institutional files were also used to complement the information obtained (e.g., prior criminal activity and detentions, psychiatric diagnosis). Some of the information (e.g., sociodemographic variables) was obtained from self-reports. The first author made the diagnosis of CD (American Psychiatric Association, 2013), after interviewing each youth and taking into consideration the institutional files (which also included the official psychiatric and psychological assessments of each youth).

The data were analyzed using the SPSS v22 (IBM Corp, 2013) software. Pearson's correlations were used to analyze associations between scale variables, Spearman's correlations were used with ordinal variables, and point-biserial correlations were used to analyze associations between nominal dichotomous variables and scale variables (Leech, Barrett, \& Morgan, 2014). Correlations were considered low if below .20, moderate if between .20 and .60 , and high if above .60. Mean inter-item correlations were deemed good if between .15 and .50 (Clark \& Watson, 1995). Corrected item-total correlations were considered satisfactory if above .20 (Nunnally \& Bernstein, 1994). Cronbach's alphas were considered good if above .70 (Cortina, 1993). Multiple regression analysis was used to predict associations 
TABLE 1: Cronbach's Alpha, Mean Inter-Item Correlation, and Corrected Item-Total Correlation Range for the Different CU Traits Measures

\begin{tabular}{lccc}
\hline & Cronbach's $\alpha$ & MIIC & CITCR \\
\hline APSD-SR CU dimension & & .29 & $.23-.59$ \\
YPI CU dimension & .68 & .43 & $.43-.60$ \\
YPI Callousness subscale & .70 & .23 & $.21-.51$ \\
YPI Unemotionality subscale & .59 & .22 & $.22-.36$ \\
YPI Remorselessness subscale & .58 & .28 & $.28-.44$ \\
YPI-S Affective dimension & .67 & .25 & $.30-.50$ \\
ICU total & .67 & .28 & $.23-.64$ \\
ICU Callousness dimension & .90 & .39 & $.30-.69$ \\
ICU Uncaring dimension & .88 & .44 & $.50-.71$ \\
ICU Unemotional dimension & .86 & .59 & $.61-.82$ \\
\hline
\end{tabular}

Note. $\mathrm{CU}=$ callous-unemotional; MIIC = mean inter-item correlation; $\mathrm{CITCR}=$ corrected item-total correlation range; APSD-SR CU = Antisocial Process Screening Device-Self-Report CU dimension; YPI CU = Youth Psychopathic Traits Inventory CU dimension; YPI-S = YPI short version; ICU = Inventory of CU Traits.

a. Item 20 of the APSD-SR not included.

with scale variables, and ordinal regression analysis was used to predict associations with ordinal variables (Leech et al., 2014). The results were considered significant if $p<.05$.

\section{RESULTS}

Our first step was to examine the reliability and internal consistency of the several selfreport CU traits measures used in the present study, namely the APSD, YPI, YPI-S, and ICU. Table 1 displays Cronbach's alpha coefficients, mean inter-item correlations, and corrected item-total correlations range for the several instruments. Item 20 ("Keeps the same friends") of the APSD-SR was removed to increase the internal consistency (see Poythress, Douglas, et al., 2006) of the CU dimension of this instrument. In general, the ICU and its subscales showed the highest internal consistency $(\alpha=.86-.90)$. Consistent with prior research, the internal consistency of the APSD CU scale was fairly low $(\alpha=.68)$. In addition, the YPI CU showed acceptable internal consistency $(\alpha=.70)$. The internal consistency of the YPI CU subscales was fairly low $(\alpha=.58-.67)$, as was the YPI-S CU scale $(\alpha=.67)$.

The next step was to analyze the inter-correlations between the different CU traits measures, and these inter-correlations are presented in Table 2. Specifically, the APSD CU scale showed the highest associations with the ICU and its subscales $(r=.44-.68, p<.001)$. In addition, the YPI CU dimension evinced more consistent correlations with the ICU and its subscales compared with the YPI-S. As shown in Table 2, the YPI CU dimension was positively correlated with the ICU Total $(r=.52, p<.001)$, Callousness $(r=.58, p<.001)$, Uncaring $(r=.36, p<.001)$, and Unemotional $(r=.14, p<.05)$ scales, while the YPI-S was only positively correlated with the Total $(r=.26, p<.001)$ and Callousness $(r=.38, p<$ .001) scales. There was some evidence for convergent validity between the Uncaring and Callous subscales of the ICU and the Remorselessness and Callous subscales of YPI CU. That is, the Uncaring subscale of the ICU correlated positively with the Remorselessness subscale of the YPI $(r=.32, p<.001)$, and the two Callous subscales from the respective measures correlated positively $(r=.43, p<.001)$. Alternatively, the unemotional subscales from each of the two scales were uncorrelated. 
TABLE 2: Inter-Correlations Between the Different CU Traits Measures

\begin{tabular}{|c|c|c|c|c|c|c|c|c|c|c|}
\hline & 1 & 2 & 3 & 4 & 5 & 6 & 7 & 8 & 9 & 10 \\
\hline 1. APSD CU & 1 & & & & & & & & & \\
\hline 2. YPI CU & $.29^{\star \star \star}$ & 1 & & & & & & & & \\
\hline 3. YPI Callo & $.34^{\star \star \star}$ & $.75^{\star \star \star}$ & 1 & & & & & & & \\
\hline 4. YPI Unem & .05 & $.76^{\star \star \star}$ & $.31^{\star \star *}$ & 1 & & & & & & \\
\hline 5. YPI Remo & $.29^{\star * *}$ & $.84^{* * *}$ & $.43^{* * *}$ & $.54^{\star \star *}$ & 1 & & & & & \\
\hline 6. YPI-S A & .11 & $.81^{* * *}$ & $.48^{* * *}$ & $.76^{\star \star \star}$ & $.69^{\star \star \star}$ & 1 & & & & \\
\hline 7. ICU Total & $.68^{* * *}$ & $.52^{* * *}$ & $.49^{* * *}$ & $.26^{\star \star \star}$ & $.46^{\star \star *}$ & $.26^{\star \star \star}$ & 1 & & & \\
\hline 8. ICU Callo & $.48^{* * *}$ & $.58^{\star * *}$ & $.43^{* * *}$ & $.40^{* * *}$ & $.53^{\star \star \star}$ & $.38^{\star \star *}$ & $.83^{\star \star \star}$ & 1 & & \\
\hline 9. ICU Uncar & $.64^{\star * \star}$ & $.36^{\star * *}$ & $.41^{\star \star \star}$ & .09 & $.32^{\star \star \star}$ & .12 & $.80^{\star \star *}$ & $.43^{\star * \star}$ & 1 & \\
\hline 10. ICU Une & $.44^{\star \star *}$ & $.14^{*}$ & $.25^{\star \star *}$ & -.02 & .08 & -.01 & $.66^{\star * *}$ & $.29^{\star * *}$ & $.47^{\star \star \star}$ & 1 \\
\hline
\end{tabular}

Note. $\mathrm{CU}=$ callous-unemotional; APSD $\mathrm{CU}=$ Antisocial Process Screening Device CU dimension; YPI CU = Youth Psychopathic Traits Inventory CU dimension; YPI Callo = YPI Callousness subscale; YPI Unem = YPI Unemotionality subscale; YPI Remo = YPI Remorselessness subscale; YPI-S A = YPI short version Affective dimension; ICU = Inventory of CU Traits; ICU Callo = ICU Callousness dimension; ICU Uncar = ICU Uncaring dimension; ICU Une = ICU Unemotional dimension.

${ }^{*} p<.05 .{ }^{* * *} p<.001$.

TABLE 3: Correlations of the Different CU Traits Measures With Other Variables

\begin{tabular}{|c|c|c|c|c|c|c|c|}
\hline & $\begin{array}{l}R P Q \\
\text { total }\end{array}$ & $\begin{array}{c}R P Q \\
\text { Reactive }\end{array}$ & $\begin{array}{c}R P Q \\
\text { Proactive }\end{array}$ & $C D$ scale & $\begin{array}{c}C D \\
\text { diagnostic }\end{array}$ & $A C O$ & ICS \\
\hline APSD CU & $.26^{\star \star \star}$ & $.18^{\star \star}$ & $.28^{\star \star \star}$ & $.29^{\star \star \star}$ & $.15^{\star}$ & $-.16^{*}$ & $.16^{\star}$ \\
\hline YPI CU & $.44^{\star \star \star}$ & $.36^{\star \star \star}$ & $.45^{\star \star \star}$ & $.47^{\star \star \star}$ & $.18^{\star \star}$ & $-.23^{\star \star \star}$ & $.19^{\star \star}$ \\
\hline YPI Callo & $.31^{\star * *}$ & $.25^{\star \star *}$ & $.32^{* \star *}$ & $.33^{\star \star *}$ & .10 & $-.19^{\star \star}$ & $.14^{*}$ \\
\hline YPI Unem & $.32^{\star \star \star}$ & $.25^{\star \star \star}$ & $.33^{\star \star *}$ & $.31^{\star \star *}$ & .13 & $-.18^{\star \star}$ & .13 \\
\hline YPI Remo & $.41^{\star \star *}$ & $.35^{\star * *}$ & $.40^{* * *}$ & $.46^{* * *}$ & $.18^{\star *}$ & $-.16^{*}$ & $.19^{\star *}$ \\
\hline YPI-S A & $.32^{\star \star \star}$ & $.29^{\star \star \star}$ & $.30 * \star *$ & $.29^{\star \star \star}$ & .08 & -.13 & .10 \\
\hline ICU Total & $.40^{* * *}$ & $.32^{* * *}$ & $.40^{* * *}$ & $.48^{* * *}$ & $.22^{\star \star *}$ & $-.21^{\star *}$ & $.24^{\star \star \star}$ \\
\hline ICU Callo & $.47^{\star \star \star}$ & $.41^{* * *}$ & $.46^{\star \star \star}$ & $.54^{\star \star \star}$ & $.19^{\star *}$ & $-.18^{* *}$ & $.26^{\star \star \star}$ \\
\hline ICU Uncar & $.29^{\star \star \star}$ & $.24^{\star \star \star}$ & $.29^{\star \star \star}$ & $.31^{\star \star \star}$ & $.18^{\star \star}$ & $-.21^{\star \star}$ & $.14^{*}$ \\
\hline ICU Une & .03 & -.05 & .08 & $.15^{\star}$ & .13 & -.07 & .10 \\
\hline
\end{tabular}

Note. $\mathrm{CU}=$ callous-unemotional; RPQ = Reactive-Proactive Aggression Questionnaire; RPQ Reactive $=\mathrm{RPQ}$ Reactive dimension; RPQ Proactive $=\mathrm{RPQ}$ Proactive dimension; $\mathrm{CD}=$ conduct disorder; $\mathrm{CD}$ scale $=D S M-5$ CD scored as a scale; $C D$ diagnostic $=D S M-5$ CD diagnostic; $A C O=$ age of crime onset; ICS = Index of Crime Seriousness; APSD CU = Antisocial Process Screening Device CU dimension; YPI CU = Youth Psychopathic traits Inventory CU dimension; YPI Callo = YPI Callousness subscale; YPI Unem = YPI Unemotionality subscale; YPI Remo = YPI Remorselessness subscale; YPI-S A = YPI Short version Affective dimension; ICU = Inventory of CU Traits; ICU Callo = ICU Callousness dimension; ICU Uncar = ICU Uncaring dimension; ICU Une = ICU Unemotional dimension; DSM-5 = Diagnostic and Statistical Manual of Mental Disorders-fifth edition. ${ }^{*} p<.05 .{ }^{* *} p<.01 .{ }^{* * *} p<.001$.

The correlations between the different $\mathrm{CU}$ traits measures with criterion were then analyzed and are presented in Table 3. In general, most of the scales showed similar patterns of correlations in the expected directions with the external variables with the exception of the ICU Unemotional dimension. That is, the ICU Unemotional dimension was unrelated to all external variables with the exception of the CD scale. Alternatively, the YPI Unemotional scale was positively correlated with the total RPQ $(r=.32, p<.001)$, reactive aggression $(r=.25, p<.001)$, proactive aggression $(r=.33, p<.001)$, the CD scale $(r=.31, p<.001)$ 
TABLE 4: Simultaneous Multiple Regression Analysis Summary of the Independent Models Predicting Aggression, CD, and Age of Crime Onset

\begin{tabular}{|c|c|c|c|}
\hline & B & SE B & $\beta$ \\
\hline \multicolumn{4}{|l|}{$\mathrm{RPQ}$ total } \\
\hline Constant & 24.34 & 3.21 & \\
\hline YPI Remo & .65 & .24 & $.19^{\star *}$ \\
\hline ICU Callo & .53 & .11 & $.35^{\star \star \star}$ \\
\hline ICU Uncar & .31 & .14 & $.16^{\star}$ \\
\hline ICU Une & -.46 & .19 & $-.16^{\star}$ \\
\hline \multicolumn{4}{|l|}{ CD scale } \\
\hline Constant & 3.36 & .44 & \\
\hline YPI Remo & .16 & .04 & $.25^{\star \star \star}$ \\
\hline ICU Callo & .11 & .02 & $.41^{* \star *}$ \\
\hline \multicolumn{4}{|l|}{$\mathrm{ACO}$} \\
\hline Constant & 13.11 & .47 & \\
\hline YPI Unem & -.08 & .03 & $-.17^{\star}$ \\
\hline ICU Uncar & -.05 & .02 & $-.20^{\star \star}$ \\
\hline
\end{tabular}

Note. $\mathrm{CD}=$ conduct disorder; $\mathrm{RPQ}=$ Reactive-Proactive Aggression Questionnaire; $\mathrm{YPI}=$ Youth Psychopathic Traits Inventory; YPI Remo = YPI Remorselessness subscale; ICU = Inventory of Callous-Unemotional Traits; ICU Callo = ICU Callousness dimension; ICU Uncar = ICU Uncaring dimension; ICU Une = ICU Unemotional dimension; $C D$ scale $=D S M-5 C D$ scored as a scale; $A C O=$ age of crime onset; YPI Unem = YPI Unemotionality subscale; $D S M-5=$ Diagnostic and Statistical Manual of Mental Disorders-fifth edition. ${ }^{\star} p<.05 .{ }^{* \star} p<.01 .{ }^{* * *} p<.001$.

and negatively related to age of onset $(r=-.18, p<.01)$. Interestingly, however, the ICU total and the Callousness and Uncaring dimensions generally showed the most consistent and highest correlations with the variables analyzed (see Table 3). The correlation between age and $\mathrm{CU}$ traits was also examined for each of the measures and their subscales to address concerns that assessment of CU traits may vary by age among incarcerated youth (Pihet, Etter, Schmid, \& Kimonis, 2015). However, only the APSD CU scale showed a fairly weak significant correlation $(r=-.15, p<.05)$. The other measures were unrelated to age.

Several simultaneous hierarchical multiple regression models were performed with the Enter method and were independently used to predict aggression, CD, and age of crime onset, and these models are presented in Table 4. The YPI CU dimension total, the YPI-S Affective dimension, and the ICU total were not included in the equations due to item overlap and because they were highly correlated $(r \geq .60)$ with the other measures (Leech et al., 2014). Thus, models only included the APSD and the dimension scales of the YPI and ICU. In addition, collinearity was checked with Tolerance and variance inflation factor (VIF). Variables that were not statistically significant were removed from the models, namely the APSD CU dimension, YPI Callousness subscale, and YPI Unemotionality subscale were removed from the aggression model; the APSD CU dimension, YPI Callousness subscale, YPI Unemotionality subscale, ICU Uncaring dimension, ICU Unemotional dimension were removed from the CD model; the APSD CU dimension, YPI Callousness subscale, YPI Remorselessness subscale, ICU Callousness dimension, and ICU Unemotional dimension were removed from the age of crime onset model.

With regard to aggression, the YPI Remorselessness scale and the ICU subscales predicted significant variance in this model, $R^{2}=.29, F(4,2016)=21.503, p<.001$. Specifically, the YPI Remorselessness scale $(\beta=.19, p=.008)$, the ICU Callousness $(\beta=.35, p<.001)$ 
TABLE 5: Ordinal Regression Analysis Summary of the Model Predicting Crime Seriousness

\begin{tabular}{lccccc}
\hline & Estimate & SE & Wald (df) & p value & $95 \% \mathrm{Cl}$ \\
\hline $\mathrm{ICS}=1$ & -3.27 & 0.62 & $27.43(1)$ & $\leq .001$ & {$[-4.49,-2.05]$} \\
$\mathrm{ICS}=2$ & -1.82 & 0.38 & $22.71(1)$ & $\leq .001$ & {$[-2.57,-1.07]$} \\
$\mathrm{ICS}=3$ & -1.04 & 0.33 & $10.00(1)$ & .002 & {$[-1.69,-0.40]$} \\
$\mathrm{ICS}=4$ & 0.01 & 0.31 & $0.00(1)$ & .968 & {$[-0.59,0.62]$} \\
$\mathrm{ICU}$ Callo & 0.06 & 0.02 & $13.30(1)$ & $\leq .001$ & {$[0.03,0.09]$} \\
\hline
\end{tabular}

Note. ICS = Index of Crime Seriousness; $d f=$ degrees of freedom; $95 \% \mathrm{CI}=95 \%$ confidence interval; ICU Callo = Inventory of Callous-Unemotional traits Callousness dimension.

and Uncaring $(\beta=-.16, p=.028)$ scales showed unique positive associations, while the Unemotional scale showed a unique negative association $(\beta=-.16, p=.014)$. In terms of the CD scale, only the YPI remorselessness $(\beta=.25, p<.001)$ and ICU callousness $(\beta=.41$, $p<.001)$ predicted scores in this model, $R^{2}=.33, F(2,2018)=54.376, p<.001$. Finally, regarding age of onset the YPI unemotional $(\beta=-.17, p=.013)$ and ICU uncaring $(\beta=-.20$, $p=.003)$ were the only significant predictors in this model, $R^{2}=.07, F(2,2018)=8.421$, $p<.001$.

All measures of CU traits (except the YPI CU dimension total, the YPI-S Affective dimension, and the ICU total mentioned above) were initially included in an ordinal model to predict crime seriousness, given the ordinal nature of the attributes associated with the crime seriousness. However, only the Callousness subscale of the ICU reached statistical significance. Because of that, the rest of the variables were removed, and the model was retested. Table 5 presents the results of the association between the Callousness subscale and crime seriousness using the ordinal regression model, $G^{2}(1)=14.461, p \leq .001, R_{\mathrm{N}}^{2}=.08$, $R_{\mathrm{CS}}^{2}=.07, R_{\mathrm{MF}}^{2}=.04$.

\section{DISCUSSION}

The aim of the present study was to examine the psychometric properties of four highly used self-report measures of CU traits (i.e., the APSD, ICU, YPI, and the YPI-S) among a single sample of justice-involved youth. Although several previous studies have compared multiple self-report measures of CU traits among a single sample, most have been limited to two separate measures. Few studies have compared the psychometric properties of these measures among a sample that is both culturally unique and justice involved. To our knowledge, the current study is the first to present findings comparing multiple self-report measures of CU traits among a Portuguese sample of incarcerated juveniles. Our findings extend those of prior research by assessing the validity of these measures among a culturally unique sample. In addition, several findings emerged from the current research that have important implications for the measurement of CU traits using the self-report method.

The current study provides some insight into the comparative utility of these distinct measures of CU traits among a particularly relevant population of youth (i.e., justice involved). In general, both the ICU and the YPI CU dimensions showed the highest levels of internal reliability compared with the APSD CU and the YPI-S Affective dimensions across all indicators of internal reliability. This is not too surprising, given previous findings regarding the internal consistency of the APSD (Poythress, Douglas, et al., 2006), and that the ICU was designed to address these limitations. When comparing the ICU with the YPI 
CU dimension, the ICU had a somewhat higher Cronbach's alpha (.90 vs. .70, respectively). Alternatively, the YPI CU dimension showed higher internal reliability when based on other indicators of internal reliability (i.e., mean inter-item correlation [MIIC] and corrected item-total correlation range [CITCR]). The ICU and the YPI seemed to perform equally well in terms of reliability among the current sample although this was somewhat dependent on how reliability was determined. However, both the ICU and YPI performed better than the YPI-S and APSD. When considering the subscales of the ICU and the YPI CU dimension, the findings from the current study suggested that the ICU subscales have greater internal reliability than those of the YPI CU subscales across all methods of assessing reliability.

The convergent validity of these measures was examined at the bivariate level. With regard to convergent validity, the ICU and the YPI CU dimension showed some of the strongest and more consistent correlations with the other measures. However, the APSD CU and the YPI-S Affective subscales were uncorrelated with one another. This places some doubts on whether these two scales are measuring the same construct. The correlations among the conceptually analogous subscales of the ICU and the YPI were somewhat inconsistent. Most notably, the ICU Unemotional and YPI Unemotionality subscales were unrelated to each other, while the Callousness subscales from both measures showed the highest degree of convergent validity.

The concurrent validity of these measures was also examined at the bivariate and multivariate levels. At the bivariate level, all four measures of CU traits showed fairly consistent associations with antisocial outcomes in the expected directions. The YPI-S Affective subscale showed the most inconsistent pattern of correlations, as it was unrelated to CD diagnosis, age of onset, and crime seriousness. While the magnitude of the correlation with CD diagnosis was strongest for the ICU, this correlation was still fairly small suggesting a weak association between CU traits and CD diagnosis in general. This is somewhat consistent with prior research. For instance, Frick et al. (2000) found that the CU scale of the APSD had the smallest association with CD compared with the Narcissism and Impulsivity scales. This may reflect cross-method effects (i.e., CD diagnosis vs. self-report), given that the correlations between $\mathrm{CU}$ traits and the $\mathrm{CD}$ scale were much stronger. In addition, due to the high percentage of $\mathrm{CD}$ diagnoses $(94.1 \%)$ in the current sample, the low correlations between CU scores and CD diagnosis may be due to a lack of variation in CD. When considering the subscales, the most notable finding was with regard to the ICU Unemotional subscale as it was unrelated to all external criteria aside from a fairly weak correlation with CD. The multivariate analyses did provide additional insights into the unique associations between the subscales and the external criteria. Based on these findings, the ICU Callousness and Uncaring subscales as well as the YPI Remorselessness subscale showed the most consistent unique associations with external criteria, with the ICU Callousness subscale being the strongest predictor of aggression, CD, and crime seriousness. Interestingly, the ICU Unemotional subscale had a significant negative association with aggression once shared variance in the other subscales was accounted for. Consistent with conclusions of Ansel et al. (2015), the findings from the current study support the view that CU traits should be seen as a multidimensional construct given the unique associations with external criteria.

These results highlight the utility of multidimensional measures of CU traits that capture the full range of the CU construct. The current study supports the notion of an overarching CU construct, as total scores from the ICU and the YPI CU dimension were associated with 
a variety of antisocial outcomes. This research provided a more nuanced look at the associations with external criteria among the subscales of these two measures. In general, the findings suggest that the ICU may be the most superior measure of CU traits. This finding is not surprising, given that it was specifically developed to provide a more comprehensive assessment of CU traits (Kimonis et al., 2008). Support was also found for the external validity of the construct of CU traits measured via self-report as the current study utilized a unique sample of detained youth in Portugal. Indeed, as the assessment of CU traits expands internationally it is important to develop valid cross-cultural measures of the CU traits to enhance our ability to make cross-cultural comparison. The current study provides further insight into the comparative utility of self-report measures of CU traits, suggesting that all four measures seem to be adaptable to distinct cultures.

The findings must be considered in light of a few limitations. First, the findings are based on cross-sectional data and, thus, the predictive utility of these measures was unable to be assessed truly. This is an important limitation as CU traits may be an essential construct in determining risk. Nonetheless, the current study still provides evidence for the utility of CU traits in assessing risk among a particularly relevant sample of incarcerated youth. Also, cross-sectional designs prevent evaluating the test-retest reliability of these measures. Second, there are several additional external criteria that were not included that may also be useful in evaluating the validity of these measures (e.g., anxiety, impulsivity, and institutional misconduct). Although we did examine a multitude of outcomes, future research should include measures of additional constructs to evaluate these measures. Third, the sample, with which the convergent validity of the four measures is assessed, is somewhat small and potentially limits statistical power. Future research should reevaluate these findings using a larger sample. Finally, despite the inclusion of four highly recognized measures of CU traits, there were several other measures of CU traits not included (e.g., CPS). The study would have also benefitted from inclusion of an additional measure of CU traits based on an alternative method such as clinical assessment (e.g., PCL:YV) or parent versions.

Limitations aside, these findings provide important insight into the utility of these selfreport measures of $\mathrm{CU}$ traits. In general, our findings support the validity of self-report measures of CU traits even among justice-involved youth. The results warrant the use of more comprehensive, multidimensional measures of CU traits in future research. However, one should not overlook the practical advantages of less time-consuming measures of CU traits, particularly in multivariate studies.

\section{REFERENCES}

American Psychiatric Association. (2013). Diagnostic and statistical manual of mental disorders (5th ed.). Arlington, VA: American Psychiatric Publishing. doi:10.1176/appi.books.9780890425596

Andershed, H., Hodgins, S., \& Tengstrom, A. (2007). Convergent validity of the Youth Psychopathic Traits Inventory (YPI): Association with the Psychopathy Checklist: Youth Version (PCL:YV). Assessment, 14, 144-154. doi:10.1177/1073191106298286

Andershed, H., Kerr, M., Stattin, H., \& Levander, S. (2002). Psychopathic traits in non-referred youths: Initial test of a new assessment tool. In E. Blaauw \& L. Sheridan (Eds.), Psychopaths: Current international perspectives (pp. 131-158). The Hague, The Netherlands: Elsevier.

Ansel, L. L., Barry, C. T., Gillen, C. T., \& Harrington, L. L. (2015). An analysis of four self-report measures of adolescent callous-unemotional traits: Exploring unique prediction of delinquency, aggression, and conduct problems. Journal of Psychopathology and Behavioral Assessment, 37, 207-216. doi:10.1007/s10862-014-9460-Z

Bijttebier, P., \& Decoene, S. (2009). Assessment of psychopathic traits in children and adolescents: Further validation of the Antisocial Process Screening Device and the Childhood Psychopathy Scale. European Journal of Psychological Assessment, 25, 157-163. doi:10.1027/1015-5759.25.3.157 
Caputo, A., Frick, P., \& Brodsky, S. (1999). Family violence and juvenile sex offending. Criminal Justice and Behavior, 26, 338-356. doi:10.1177/0093854899026003004

Clark, L., \& Watson, D. (1995). Constructing validity: Basic issues in objective scale development. Psychological Assessment, 7, 309-319. doi:10.1037/1040-3590.7.3.309

Colins, O., Bijttebier, P., Broekaert, E., \& Andershed, H. (2014). Psychopathic-like traits among detained female adolescents: Reliability and validity of the Antisocial Process Screening Device and the Youth Psychopathic Traits Inventory. Assessment, 21, 195-209. doi:10.1177/1073191113481997

Colins, O., Noom, M., \& Vanderplasschen, W. (2012). Youth Psychopathic Traits Inventory-Short version: A further test of the internal consistency and criterion validity. Journal of Psychopathology and Behavioral Assessment, 34, 476-486. doi:10.1007/s10862-012-9299-0

Cooke, D. J., \& Michie, C. (2001). Refining the construct of psychopathy: Towards a hierarchical model. Psychological Assessment, 13, 171-188.

Cortina, J. (1993). What is coefficient alpha? An examination of theory and applications. Journal of Applied Psychology, 78, 98-104. doi:10.1037/0021-9010.78.1.98

Dadds, M. R., Fraser, J., Frost, A., \& Hawes, D. J. (2005). Disentangling the underlying dimensions of psychopathy and conduct problems in childhood: A community study. Journal of Consulting and Clinical Psychology, 73, 400-410. doi:10.1037/0022-006X.73.3.400

Declercq, F., Markey, S., Vandist, K., \& Verhaeghe, P. (2009). The Youth Psychopathic Trait Inventory: Factor structure and antisocial behaviour in non-referred 12-17-year-olds. The Journal of Forensic Psychiatry \& Psychology, 20, 577-594. doi:10.1080/14789940802651757

Dolan, M., \& Rennie, C. (2006). Psychopathy Checklist: Youth Version and Youth Psychopathic Trait Inventory: A comparison study. Personality and Individual Differences, 41, 779-789. doi:10.1016/j.paid.2006.03.021

Essau, C., Sasagawa, S., \& Frick, P. (2006). Callous-unemotional traits in a community sample of adolescents. Assessment, 13, 454-469. doi:10.1177/1073191106287354

Fanti, K. A., Frick, P. J., \& Georgiou, S. (2009). Linking callous-unemotional traits to instrumental and non-instrumental forms of aggression. Journal of Psychopathology and Behavioral Assessment, 31, 285-298. doi:10.1007/s10862-0089111-3

Forth, A. E., Kosson, D. S., \& Hare, R. D. (2003). Hare Psychopathy Checklist: Youth Version. North Tonawanda, NY: Multi-Health Systems.

Frick, P. J., Bodin, S. D., \& Barry, C. T. (2000). Psychopathic traits and conduct problems in community and clinic-referred samples of children: Further development of the psychopathy screening device. Psychological Assessment, 12, 382-393. doi:10.1037/1040-3590.12.4.382

Frick, P. J., \& Hare, R. D. (2001). Antisocial Process Screening Device (APSD). Toronto, Ontario, Canada: Multi-Health Systems.

Frick, P. J., \& Ray, J. V. (2015). Evaluating callous-unemotional traits as a personality construct. Journal of Personality, 83, 710-722. doi:10.1111/jopy.12114

Frick, P. J., Ray, J. V., Thornton, L. C., \& Kahn, R. E. (2014). Can callous-unemotional traits enhance the understanding, diagnosis, and treatment of serious conduct problems in children and adolescents? A comprehensive review. Psychological Bulletin, 140, 1-57. doi:10.1037/a0033076

Frick, P. J., Stickle, T. R., Dandreaux, D. M., Farrell, J. M., \& Kimonis, E. R. (2005). Callous-unemotional traits in predicting the severity and stability of conduct problems and delinquency. Journal of Abnormal Child Psychology, 33, 471-487. doi:10.1007/s10648-005-5728-9

Hare, R. D. (2003). The Hare Psychopathy Checklist-Revised. Toronto, Ontario, Canada: Multi-Health Systems.

Hawes, S. W., Byrd, A. L., Henderson, C. E., Gazda, R. L., Burke, J. D., Loeber, R., \& Pardini, D. A. (2014). Refining the parent-reported Inventory of Callous-Unemotional Traits in boys with conduct problems. Psychological Assessment, 26, 256-266. doi:10.1037/a0034718

Hillege, S., Das, J., \& de Ruiter, C. (2010). The Youth Psychopathic Traits Inventory: Psychometric properties and its relation to substance use and interpersonal style in a Dutch sample of non-referred adolescents. Journal of Adolescence, 33 , 83-91. doi:10.1016/j.adolescence.2009.05.006

IBM Corp. (2013). IBM SPSS Statistics for Windows, Version 22.0. Armonk, NY: Author.

Kahn, R. E., Byrd, A. L., \& Pardini, D. A. (2013). Callous-unemotional traits robustly predict future criminal offending in young men. Law and Human Behavior, 37, 87-97. doi:10.1037/b0000003

Kimonis, E., Frick, P., Skeem, J., Marsee, M., Cruise, K., Muñoz, L., \& Morris, A. (2008). Assessing callous-unemotional traits in adolescent offenders: Validation of the Inventory of Callous-Unemotional Traits. International Journal of Law and Psychiatry, 31, 241-252. doi:10.1016/j.ijlp.2008.04.002

Kosson, D. S., Cyterski, T. D., Steuerwald, B. L., Neumann, C. S., \& Walker-Matthews, S. (2002). The reliability and validity of the Psychopathy Checklist: Youth Version (PCL:YV) in nonincarcerated adolescent males. Psychological Assessment, 14, 97-109. doi:10.1037/1040-3590.14.1.97

Leech, N., Barrett, K., \& Morgan, G. (2015). SPSS for intermediate statistics: Use and interpretation (5th ed.). New York, NY: Lawrence Erlbaum Associates, Inc. 
Lynam, D. R. (1997). Pursuing the psychopath: Capturing the fledgling psychopath in a nomological net. Journal of Abnormal Psychology, 106, 425-438. doi:10.1037/0021-843X.106.3.425

Marsee, M. A., Silverthorn, P., \& Frick, P. J. (2005). The association of psychopathic traits with aggression and delinquency in non-referred boys and girls. Behavioral Sciences \& the Law, 23, 803-817. doi:10.1002/bs1.662

Muñoz, L., \& Frick, P. (2007). The reliability, stability, and predictive utility of the self-report version of the Antisocial Process Screening Device. Scandinavian Journal of Psychology, 48, 299-312. doi:10.1111/j.1467-9450.2007.00560.x

Nunnally, J., \& Bernstein, I. (1994). Psychometric theory. New York, NY: McGraw-Hill.

Pechorro, P., Andershed, H., Ray, J., Maroco, J., \& Gonçalves, R. (2015). Validation of the Youth Psychopathic Traits Inventory and Youth Psychopathic Traits Inventory-Short among incarcerated juvenile delinquents. Journal of Psychopathology and Behavioral Assessment, 37, 576-586. doi:10.1007/s10862-015-9490-1

Pechorro, P., Hidalgo, V., Nunes, C., \& Jiménez, L. (2015). Confirmatory factor analysis of the Antisocial Process Screening Device: Self-report among incarcerated male juvenile offenders. International Journal of Offender Therapy and Comparative Criminology. Advance online publication. doi:10.1177/0306624X15588903

Pechorro, P., Maroco, J., Poiares, C., \& Vieira, R. (2013). Validation of the Portuguese version of the Antisocial Process Screening Device Self-Report with a focus on delinquent behavior and behavior problems. International Journal of Offender Therapy and Comparative Criminology, 57, 112-126. doi:10.1177/0306624X11427174

Pechorro, P., Ray, J., Barroso, R., Maroco, J., \& Gonçalves, R. (2016). Validation of the Inventory of Callous-Unemotional Traits among Portuguese juvenile delinquents. International Journal of Offender Therapy and Comparative Criminology, 60, 349-365. doi:10.11770306624X14551256

Pechorro, P., Ray, J., Raine, A., Maroco, J., \& Gonçalves, R. (2015). The Reactive-Proactive Aggression Questionnaire: Validation among a Portuguese sample of incarcerated juvenile delinquents. Journal of Interpersonal Violence. Advance online publication. doi:10.1177/0886260515590784

Pihet, S., Etter, S., Schmid, M., \& Kimonis, E. R. (2015). Assessing callous-unemotional traits in adolescents: Validity of the Inventory of Callous-Unemotional Traits across gender, age, and community/institutionalized status. Journal of Psychopathology and Behavioral Assessment, 37, 407-421. doi:10.1007/s10862-014-9472-8

Poythress, N. G., Dembo, R., Wareham, J., \& Greenbaum, P. E. (2006). Construct validity of the Youth Psychopathic Traits Inventory (YPI) and the Antisocial Process Screening Device (APSD) with justice-involved adolescents. Criminal Justice and Behavior, 33, 26-55. doi:10.1177/0093854805282518

Poythress, N. G., Douglas, K., Falkenbach, D., Cruise, K., Lee, Z., Murrie, D., \& Vitacco, M. (2006). Internal consistency reliability of the self-report Antisocial Process Screening Device. Assessment, 13, 107-113. doi:10.1177/1073191105284279

Raine, A., Dodge, K., Loeber, R., Gatzke-Kopp, L., Lynam, D., Reynolds, C., . . . Liu, J. (2006). The Reactive-Proactive Aggression Questionnaire: Differential correlates of reactive and proactive aggression in adolescent boys. Aggressive Behavior, 32, 159-171. doi:10.1002/ab.20115

Roose, A., Bijttebier, P., Decoene, S., Claes, L., \& Frick, P. J. (2010). Assessing the affective features of psychopathy in adolescence: A further validation of the Inventory of Callous and Unemotional Traits. Assessment, 17, 44-57. doi:10.1177/1073191109344153

Roose, A., Bijttebier, P., Van der Oord, S., Claes, L., \& Lilienfeld, S. O. (2013). Psychopathic traits in youth and associations with temperamental features: Results from a performance-based measure. Journal of Individual Differences, 34, 1-7. doi:10.1027/1614-0001/a000090

Seals, R. W., Sharp, C., Ha, C., \& Michonski, J. D. (2012). The relationship between the Youth Psychopathic Traits Inventory and psychopathology in a U.S. community sample of male youth. Journal of Personality Assessment, 94, $232-243$. doi:10.1080/00223891.2011.650303

Skeem, J. L., \& Cauffman, E. (2003). Views of the downward extension: Comparing the youth version of the Psychopathy Checklist with the Youth Psychopathic Traits Inventory. Behavioral Sciences \& the Law, 21, 737-770. doi:10.1002/ bsl.563

Skeem, J. L., Polaschek, D. L., Patrick, C. J., \& Lilienfeld, S. O. (2011). Psychopathic personality: Bridging the gap between scientific evidence and public policy. Psychological Science in the Public Interest, 12, 95-162. doi:10.1177/1529100611426706

Skilling, T. A., Quinsey, V. L., \& Craig, W. M. (2001). Evidence of a taxon underlying serious antisocial behavior in boys. Criminal Justice and Behavior, 28, 450-470. doi:10.1177/009385480102800404

Vahl, P., Colins, O. F., Lodewijks, H. P., Markus, M. T., Doreleijers, T. A., \& Vermeiren, R. R. (2014). Psychopathic-like traits in detained adolescents: Clinical usefulness of self-report. European Child \& Adolescent Psychiatry, 23, 691-699. doi:10.1007/s00787-013-0497-4

van Baardewijk, Y., Andershed, H., Stegge, H., Nilsson, K., Scholte, E., \& Vermeiren, R. (2010). Development and tests of short versions of the Youth Psychopathic Traits Inventory and the Youth Psychopathic Traits Inventory-Child Version. European Journal of Psychological Assessment, 26, 122-128. doi:10.1027/1015-5759/a000017

Vaughn, M. G., DeLisi, M., Beaver, K. M., Wexler, J., Barth, A., \& Fletcher, J. (2011). Juvenile psychopathic personality traits are associated with poor reading achievement. Psychiatric Quarterly, 82, 177-190. doi:10.1007/s11126-010-9162-y 
Vaughn, M. G., \& Howard, M. O. (2005). Self-report measures of juvenile psychopathic personality traits: A comprehensive review. Journal of Emotional and Behavioral Disorders, 13, 152-162.

Vitacco, M. J., Rogers, R., \& Neumann, C. S. (2003). The Antisocial Process Screening Device: An examination of its construct and criterion-related validity. Assessment, 10, 143-150. doi:10.1177/1073191103252347

White, J., Moffitt, T., Caspi, A., Jeglum-Bartusch, D., Needles, D., \& Stouthamer-Loeber, M. (1994). Measuring impulsivity and examining its relation to delinquency. Journal of Abnormal Psychology, 103, 192-205.

James V. Ray is an assistant professor in the Department of Criminal Justice at the University of Texas at San Antonio. His research interests include juvenile delinquency and juvenile justice, personality and offending, psychopathy, and developmental criminology.

Pedro Pechorro is a postdoctoral researcher at the Center for Research in psychology at the School of Psychology, University of Minho, Portugal, with a grant from the Portuguese Foundation for Science and Technology. His research interests include juvenile delinquency, juvenile psychopathy, and developmental criminology.

Rui Abrunhosa Gonçalves is an associate professor at the School of Psychology in the University of Minho (Braga, Portugal) where in 1997 he took his $\mathrm{PhD}$ in forensic and legal psychology. He has consistently researched and published on the topics of violent and dangerous offenders, namely psychopaths, sexual abusers, and spouse abusers. He also works as a forensic psychologist at the Counselling Unit of Forensic Psychology in the University of Minho. 